\title{
COMENTARIO A LA STC 6/2012, DE 18 DE ENERO DE 2012: LAS COMPETENCIAS DE LAS COMUNIDADES AUTÓNOMAS PARA LA CONSERVACIÓN DE LAS OBRAS ARTÍSTICAS DEPOSITADAS EN INSTITUCIONES MUSEÍSTICAS
}

\author{
ELOY COLOM PIAZUELO \\ Catedrático acreditado de Derecho Administrativo \\ Universidad de Zaragoza
}

SUMARIO.-

I. Introducción: descripción del supuesto de hecho sobre el que se pronuncia el TC y cómo surge el conflicto competencial entre las comunidades autónomas catalana y aragonesa.

II. Admisión de la utilización del conflicto positivo de competencias para determinar a qué Comunidad Autónoma corresponde la titularidad de la competencia para la conservación de las obras artísticas depositadas en instituciones museísticas catalanas.

III. Delimitación del objeto del conflicto competencial: exclusión por el TC de las cuestiones cuya resolución corresponde a los tribunales ordinarios.

IV. Resolución del conflicto de competencias a favor de la Comunidad Autónoma de Cataluña y consideración de que es la competente para conservar las obras artísticas depositadas en las instituciones museísticas ubicadas en su territorio. Alcance del fallo.

V. La atribución de la competencia para la conservación de las obras artísticas en fondos museísticos catalanes a la Generalitat de Catalunya no queda afectada por la potestad para recuperar el patrimonio cultural aragonés fuera de su territorio atribuida a la Comunidad Autónoma de Aragón en su Estatuto de Autonomía. 
La reciente Sentencia del Tribunal Constitucional 6/2002, de 18 de enero de 2012 (en adelante, STC 6/2002), que ha resuelto un conflicto positivo de competencias planteado entre las Comunidades Autónomas de Cataluña y Aragón, se ha pronunciado sobre una cuestión de gran relevancia en el ámbito de la conservación de las obras artísticas depositadas temporalmente en instituciones museísticas. En concreto, en ella se ha afirmado que la Administración autonómica competente para su conservación es aquélla en cuyo territorio se encuentren ubicadas dichas obras ${ }^{1}$. No obstante, el alcance de tal declaración no puede separarse de las características singulares del supuesto de hecho sobre el que se pronuncia el TC y del objeto del propio proceso constitucional delimitado en la STC 6/2012. Alcance que se examinará en los siguientes apartados y cuya determinación es el objeto principal de este comentario.

Para facilitar la comprensión de la STC 6/2002 primero se expondrá el supuesto sobre el que se ha pronunciado el Tribunal y la razón por la que se ha planteado el conflicto de competencias (I). A continuación, cómo el conflicto de competencias es el cauce adecuado para resolver el litigio planteado por ambas Comunidades, según se afirma en la propia STC 6/2012 (II); y cuál es el objeto del conflicto, dado que sobre una parte del mismo no se pronunciará el TC (III). Y, finalmente, se examinará la decisión del TC sobre qué Comunidad Autónoma es la competente para la conservación de las obras artísticas (IV); y cómo afecta este fallo a la previsión contenida en el Estatuto de Autonomía de Aragón relativa a que los poderes públicos deben procurar reintegrar al territorio aragonés el patrimonio artístico disperso $(\mathrm{V})$.

\section{INTRODUCCIÓN: DESCRIPCIÓN DEL SUPUESTO DE HECHO SOBRE EL QUE SE PRONUNCIA EL TC Y CÓMO SURGE EL CONFLICTO COMPETENCIAL ENTRE LAS COMUNIDADES AUTÓNOMAS CATALANA Y ARAGONESA}

Las obras artísticas sobre las que se pronuncia la STC 6/2002 y que fueron depositadas en instituciones museísticas catalanas proceden del Monasterio de Sigena situado en la provincia de Huesca. Dicho Monasterio fue declarado monumento nacional por Orden

1 A la STC 6/2012 se han presentado dos votos particulares. El primero de ellos formulado por la magistrada Elisa Pérez Vera y al que se adhiere el magistrado Ramón Rodríguez Arribas; y el segundo por el magistrado Francisco José Hernando Santiago y al que se adhiere el magistrado Francisco Pérez de los Cobos Orihuel. Ambos votos particulares eran partidarios de la inadmisión del conflicto de competencias y a ellos se hará referencia en el comentario de esta STC.

En relación con los bienes de interés cultural y los diversos problemas jurídicos planteados a los que se hace referencia en este comentario vid., con carácter general, J.M. ALEGRE AVILA, Evolución y régimen jurídico del patrimonio histórico, Ministerio de Cultura, Madrid, 1994; C. BARRERO RODRIGUEZ, La ordenación jurídica del patrimonio histórico, Civitas, Madrid, 1990; J.A. ALVAREZ ALVAREZ, Estudios sobre el patrimonio histórico español y la Ley de 25 de junio de 1985, Civitas, Madrid, 1989; M.ALONSO IBAÑEZ, El patrimonio histórico. Destino público y valor cultural, Civitas, Madrid, 1992; F. BENITEZ DE LUGO Y GUILLEN, El patrimonio cultural español, Comares, Granada, 1995; y J. GARCIA FERNANDEZ, Estudios sobre el derecho del patrimonio histórico, Colegio de Registradores de la Propiedad y Mercantiles de España, Madrid, 2008 
de 28 de marzo de 1923 (Gaceta de Madrid de 5 de abril de 1923)². Esta declaración comprendía el templo, el claustro y su sala capitular, el palacio prioral, el refectorio, el dormitorio antiguo, la sala de la reina y la parte subsistente de la fortificación. Y esa declaración se fundamentaba, entre otras razones, en la existencia en las partes del Monasterio citadas de numerosas obras artísticas, tal y como se resaltaba expresamente en los informes previos de la Real Academia de Bellas Artes de San Fernando y de la Real Academia de la Historia (Gaceta de Madrid de 12 de abril de 1923). Así, en el informe de la Academia de Bellas Artes se destacaba la sala capitular, con su decoración y pinturas murales, artesonados, portadas y esculturas, pudiéndose decir otro tanto de la sala prioral y de la llamada sala de la reina, y de los retablos, sillería y sepulcros que contenía el Monasterio. Y en el informe de la Real Academia de la Historia se resaltaban también como justificativo de la declaración como monumento las partes principales del Monasterio y las pinturas, retablos, retratos existentes en ellos y otras obras varias, artísticas y de recuerdo histórico ${ }^{3}$.

Esta declaración como monumento realizada en el año 1923 no quedó afectada por la aprobación de la Ley de Patrimonio Histórico Español de 1985 (en adelante, LPHE), puesto que en su Disposición adicional primera se indica que los bienes que con anterioridad hubieran sido declarados histórico-artísticos o incluidos en el Inventario del patrimonio artístico y arqueológico de España pasan a tener la consideración y a denominarse bienes de interés cultural. Por otra parte, entre los bienes de interés cultural enumerados en el art. 15 de la LPHE se mencionan los monumentos ${ }^{4}$. Tampoco ha quedado afectada esta declaración por la aprobación de la legislación aragonesa de patrimonio cultural ${ }^{5}$.

El Monasterio de Sigena fue destruido por un incendio durante la guerra civil. Ello provocó que las obras artísticas del Monasterio que no desaparecieron y que se mencionaban en los informes anteriormente citados (pinturas murales, cuadros, féretros, etc.), fueran depositadas en diversas instituciones museísticas para su conservación o restauración, algunas de ellas ubicadas en Cataluña.

Al tratarse de un monumento nacional, el edificio del Monasterio fue restaurado en las décadas siguientes; restauraciones que han continuado realizándose después por la Co-

2 La declaración ha sido complementada posteriormente. Así, se ha aprobado la Orden de 5 de abril de 2002, del Departamento de Cultura y Turismo de la Comunidad Autónoma de Aragón, por la que se completa la declaración originaria de bien de interés cultural del denominado Real Monasterio de Santa María de Sigena en Villanueva de Sijena (Huesca), conforme a la Disposición transitoria primera de la Ley 3/1999, de 10 de marzo, de patrimonio cultural aragonés (BOA 22/04/2002). Dicha ampliación tiene por objeto fundamentalmente determinar el entorno del Monasterio sometido a protección..

3 Una descripción del Monasterio de Sigena antes de su destrucción en la guerra civil puede encontrarse en M. DE PANO Y RUATA, Real Monasterio de Santa María de Sijena, Caja Inmaculada, Zaragoza, 2004.

4 En el art. 15.1 de la LPHE se definen los monumentos como aquellos bienes inmuebles que constituyen realizaciones arquitectónicas o de ingeniería, u obras de escultura colosal siempre que tengan interés histórico, artístico, científico o social.

5 Así, en la Disposición transitoria primera de la Ley aragonesa 3/1999, de 10 de marzo, de patrimonio cultural, se dice que los bienes de interés cultural ubicados en la Comunidad Autónoma que hubieren sido declarados como tal con anterioridad a la entrada en vigor de esta Ley, pasarán a tener la consideración de bienes de interés cultural o conjuntos de interés cultural 
munidad Autónoma de Aragón prácticamente hasta la actualidad ${ }^{6}$. La reapertura del Monasterio conllevó la devolución de parte de las obras artísticas por las instituciones donde estaban depositadas. Pero el cierre del Monasterio en el año 1970 por el traslado de las religiosas a otro Monasterio provocó que de nuevo fueran depositadas temporalmente algunas de ellas en instituciones museísticas catalanas para asegurar su conservación ${ }^{7}$.

Las actuaciones descritas se realizaron antes de la aprobación de la Constitución de 1978 y la creación de las Comunidades Autónomas y, por lo tanto, las competencias sobre patrimonio histórico ejercitadas sobre las obras artísticas del Monasterio correspondían al Estado. Desde esta perspectiva resultaba indiferente que el edificio del Monasterio se encontrara en la provincia aragonesa de Huesca y que los depósitos se hicieran efectivos en instituciones museísticas catalanas.

La cuestión se plantea desde la creación de las Comunidades Autónomas de Aragón y Cataluña y la asunción por las mismas de las competencias en materia de conservación del patrimonio histórico dentro de su territorio. A partir de este momento, la Comunidad Autónoma de Aragón ha asumido competencias sobre patrimonio histórico y, en consecuencia, sobre el edificio del Monasterio y su restauración y reintegración de las obras artísticas que forman parte de él; y la Comunidad Autónoma de Cataluña la competencia sobre la conservación de las diversas obras artísticas procedentes del Monasterio y depositadas en las instituciones museísticas situadas en su territorio.

La aparición de dos Administraciones con competencia cada una de ellas en una parte del supuesto de hecho descrito exige una colaboración entre las mismas, tal y como se indica en el f.j. 8 de la STC 6/2012 comentada. Y todo ello para hacer efectiva una realidad que ha venido sucediendo desde el año 1936 y que ha consistido en que las obras artísticas del Monasterio se han depositado fuera de él para su conservación y restauración cuando ha sido destruido o ha sido cerrado y han vuelto a reintegrarse al Monasterio cuando se ha reabierto o restaurado.

El conflicto de competencias entre las dos Administraciones autonómicas ha surgido cuando la Administración catalana compró a la comunidad religiosa del Monasterio en el año 1983 una parte de los bienes depositados en el Museo Diocesano de Lérida y en el año 1992 otra parte de las depositadas en el Museo Nacional de Arte de Cataluña y en el Centro de restauración de la Generalitat. Dicha compra no se notificó ni al Estado ni a la Comunidad Autónoma de Aragón. Ante esta situación y en el momento que tuvo conocimiento de la venta, la Administración aragonesa, en cuyo territorio se ubicaba el Monasterio, ejercitó el derecho de retracto previsto en la legislación de patrimonio histórico en los años 1997 y 1998 con el fin de adquirir dichas obras artísticas. Actuación que se fundamentaba en las competencias que tenía en materia de patrimonio histórico y en

6 En el Boletín oficial del Estado aparecen publicadas diversas Ordenes de aprobación de proyectos de obras del Monasterio de Sigena. Pueden mencionarse, por ejemplo, las Ordenes de 18 de octubre de 1943 (BOE 11/11/1943), de 25 de abril de 1950 (BOE 15/6/1950), 25 de noviembre de 1953 (BOE 3/5/1954) y 8 de noviembre de 1955 (BOE 30/11/1955). También se han publicado en el Boletín Oficial de Aragón anuncios de diversas obras de restauración del Monasterio (BOA 19/08/2002 y 21/11/2003)

7 Una descripción de las diversas vicisitudes de algunas de las obras artísticas procedentes del Monasterio de Sigena después de su destrucción en la guerra civil puede encontrarse en A.NAVAL MAS, Patrimonio emigrado, Publicaciones y Ediciones del Alto Aragón, Huesca, 1999, págs. 189 y ss. 
la reintegración de tales obras al Monasterio. Las resoluciones aragonesas en las que se notificaba el ejercicio del derecho de retracto fueron rechazadas por la Comunidad Autónoma de Cataluña por entender que interferían en sus competencias sobre conservación de las obras artísticas situadas dentro de su territorio; y acordó dirigir a la Diputación General de Aragón requerimiento de incompetencia. Requerimiento que fue rechazado por la Comunidad Autónoma de Aragón. Ante ello se planteó un conflicto positivo de competencias frente a las resoluciones administrativas aragonesas. Utilización de este procedimiento ante el TC que se ha admitido en la STC 6/2012, como se indicará en el apartado siguiente.

\section{ADMISIÓN DE LA UTILIZACIÓN DEL CONFLICTO POSITIVO DE COMPETENCIAS PARA DETERMINAR A QUÉ COMUNIDAD AUTÓNOMA CORRESPONDE LA TITULARIDAD DE LA COMPETENCIA PARA LA CONSERVACIÓN DE LAS OBRAS ARTÍSTICAS DEPOSITADAS EN INSTITUCIONES MUSEÍSTICAS CATALANAS}

La primera cuestión que se plantea el TC en la STC 6/2012 es si el conflicto positivo de competencias es el cauce procesal adecuado para pronunciarse sobre cuál es la Comunidad Autónoma competente para ejercitar las competencias de conservación de las obras depositadas en instituciones museísticas catalanas. Cuestión que resuelve afirmativamente, dada la jurisprudencia constitucional dictada al respecto. Así, en la citada Sentencia se afirma que el conflicto es posible plantearlo si una Comunidad Autónoma ha dictado una resolución que afecte y condicione el ejercicio de competencias que corresponden a otra Comunidad sin respetar el orden de distribución de competencias, y con dicha resolución se cuestiona la definición o delimitación de los títulos competenciales en litigio. Y en este caso se darían tales circunstancias, puesto que la Administración aragonesa ha ejercitado un derecho de retracto sobre unas obras artísticas compradas por la Generalitat de Catalunya; adquisición que se realizó en el ejercicio de la competencia estatutaria de protección del patrimonio histórico y artístico que le correspondía y que se vería afectada de prosperar el retracto ${ }^{8}$.

8 Por el contrario, en el primer voto particular a la STC 6/2012 formulado por el magistrado Elisa Pérez Vera y al que se adhiere el Magistrado Ramón Rodríguez Arribas, era partidario de la inadmisión, al carecer de relevancia constitucional y poder pronunciarse los tribunales ordinarios aplicando las previsiones de los Estatutos catalán y aragonés sobre la competencia catalana sobre patrimonio cultural y la competencia aragonesa para la recuperación o regreso de dicho patrimonio. De forma similar en el segundo voto particular a la STC 6/2012 formulado por el magistrado Francisco José Hernando Santiago y al que se adhiere el magistrado Francisco Pérez de los Cobos Orihuel, se considera que no se está ante un problema de definición de los límites de las respectivas competencias autonómicas, sino de verificación de su ejercicio concreto, cuya resolución compete a los tribunales ordinarios; de ahí que las partes aleguen argumentos de legalidad ordinaria, tales como que los bienes no son de interés cultural, o que los mismos no pueden ser objeto del derecho de retracto, etc. 
En concreto, en la STC 6/2012 se dice que la jurisprudencia del TC ha ido configurando un concepto amplio de conflicto positivo de competencias a partir de su regulación en los arts. 62 a 67 de la Ley Orgánica del Tribunal Constitucional, afirmando que en este tipo de proceso no resulta indispensable que el ente que los formaliza recabe para sí la competencia ejercida por otro; basta que entienda que una disposición, resolución o acto emanados de ese otro ente no respeta el orden de competencias establecido en el bloque de la constitucionalidad y, en el caso de las Comunidades Autónomas, además, que tal disposición, resolución o acto afecte a su ámbito de autonomía condicionando o configurando sus competencias de una forma que juzga contrarias a este orden competencial. Así, en el ámbito procesal propio de los conflictos constitucionales de competencia cabe, tanto la reivindicación de la titularidad del acto controvertido, cono la denuncia de los excesos en el ejercicio de una competencia ajena siempre que ese exceso vulnere el sistema de distribución de competencias diseñado en el bloque de la constitucionalidad (SSTC 243/1993, de 15 de julio, f.j. 2, y 87/1997, de 24 de abril, f.j.2).

Y sigue diciendo la STC 6/2012 comentada, f.j. 2, que el objeto y los límites del conflicto positivo de competencia se han interpretado con un criterio amplio, comprensivo no sólo de los supuestos que cabría calificar como normales, en los que el ente que plantea el conflicto ejerce una verdadera vindicatio potestatis por considerarse despojado de una competencia que le corresponde, sino también de aquellos otros supuestos en los que no se reivindica stricto sensu una competencia como propia, sino que se pretende la anulación del acto o disposición objeto del conflicto porque no ha respetado el orden de competencias establecido, en menoscabo de las que corresponden al ente que promueve el conflicto (ATC 886/1988, de 5 de julio, f.j 1)

En todo caso, sigue diciendo la STC comentada, la controversia debe afectar a la definición o delimitación de los títulos competenciales en litigio y, más exactamente, a la delimitación de los títulos contenida en la Constitución, los Estatutos de Autonomía o las leyes del bloque de la constitucionalidad que delimitan las competencias estatales y autonómicas (STC 243/1993, f.j.2). Condición que se entiende cumplida por el TC en el caso enjuiciado (f.j.4, STC 6/2012)

Finalmente, en la STC 6/2012 se dice que no impide la utilización de este cauce procesal el hecho de que el conflicto no surja en relación con una disposición propiamente dicha. En particular, en la STC 6/2012, f.j. 4, se afirma que el conflicto de competencias se plantea contra disposiciones y por tales debe realizarse una interpretación amplia, comprendiendo las resoluciones en las que se ejerce el derecho de retracto, pues según una consolidada jurisprudencia lo importante a estos efectos no es tanto su naturaleza o la forma del acto como la real existencia de una controversia o disputa ante un evidente ejercicio de supuestamente lesivo del orden constitucional (por todas, STC 101/1995, de 20 de junio, f.j.6)

Partiendo de la utilización adecuada de este cauce procesal, a continuación en la STC 6/2012 comentada se delimita el objeto conflicto sobre el que se va a pronunciar y excluyen las restantes cuestiones planteadas por las partes. Delimitación que resulta relevante para comprender el alcance del fallo, tal y como se indicará en el apartado siguiente. 


\section{DELIMITACIÓN DEL OBJETO DEL CONFLICTO COMPETENCIAL: EXCLUSIÓN POR EL TC DE LAS CUESTIONES CUYA RESOLUCIÓN CORRESPONDE A LOS TRIBUNALES ORDINARIOS}

La STC 6/2012 se pronuncia exclusivamente sobre la determinación de la Comunidad Autónoma competente para la conservación de las obras artísticas depositadas en las instituciones museísticas catalanas. El resto de cuestiones planteadas en relación con dichas obras es excluido de cualquier pronunciamiento por corresponder su resolución a los tribunales ordinarios. Esta exclusión condiciona considerablemente el alcance del fallo. De ahí que se exponga a continuación los puntos sobre los que no se pronuncia el TC y que son relevantes para la interpretación de la Sentencia.

Las principales cuestiones excluidas por el TC son las siguientes. La primera de ellas hace referencia a si las obras artísticas se califican como partes integrantes de un bien inmueble de interés cultural, que es el Monasterio de Sigena, o como bienes muebles independientes depositados en instituciones museísticas. La segunda y vinculada a la anterior, es si las obras artísticas están calificadas expresamente como bienes de interés cultural. Y, finalmente, si se ha respetado la legislación de patrimonio histórico al comprar la Administración catalana las obras históricas y si se han respetado las normas reguladoras del derecho de retracto.

Estas cuestiones se plantean tanto por la Administración catalana como la aragonesa. Así, para justificar la corrección de su actuación la Administración catalana parte de la calificación de las obras artísticas como bienes muebles independientes y cómo los mismos no han sido declarados expresamente de interés cultural, por lo que no resulta procedente el ejercicio del derecho de retracto, al limitarse este derecho a los bienes de interés cultural (antecedente 3 de la STC 6/2012). En cambio, la Administración aragonesa entiende que estas obras artísticas son partes del bien inmueble denominado Monasterio de Sigena y, en consecuencia, la declaración de interés cultural abarcaría también a las mismas, y podría ejercitarse el derecho de retracto. (f.j. 2 de la STC 6/2012). Además, la Administración aragonesa alega diversos incumplimientos de la legislación reguladora del derecho de retracto.

Sobre estas cuestiones el TC no se va a pronunciar. Como se indica en el f.j 2 de la STC 6/2012, deben excluirse, dado su carácter fáctico o de legalidad ordinaria, pues ciertamente atienden a la calificación de los bienes y a eventuales vicios de legalidad en el proceso de enajenación; y la verificación de dichos requisitos corresponde en exclusiva a los tribunales ordinarios, a los que ya ha acudido la entidad promotora catalana del conflicto.

Esta exclusión de las cuestiones señaladas resulta de singular trascendencia y determinan en última instancia el alcance del fallo de la STC 6/2002, como se indicará en el apartado siguiente. Así, al no pronunciarse el TC sobre la calificación de las obras artísticas — si son parte de un bien inmueble declarado de interés cultural o bienes muebles independientes no declarados de interés cultural — ni sobre la legalidad del ejercicio del derecho de retracto, la STC únicamente alude al supuesto específico de quién es la Comunidad Autónoma competente para continuar conservando las obras artísticas en las condiciones que se venían realizando, sin pronunciarse sobre la calificación de tales 
obras, la necesidad de reintegrarlas al Monasterio, su titularidad o cualquier otro aspecto relativo a las mismas?.

Es preciso advertir que la calificación de las obras artísticas resulta relevante para conocer su régimen jurídico y las competencias de las Administraciones sobre las mismas, tal y como han declarado los tribunales ordinarios. En este sentido puede mencionarse, por ejemplo, la Sentencia del Tribunal Supremo de la Sala de lo Contencioso, Sección Cuarta, de 22 de julio de 2009 (Ar. 598 de 2010), que se pronunció sobre si era posible imponer limitaciones a los inmuebles colindantes con una plaza en la que se había ubicado un estatua colosal de Dalí. La admisibilidad de tales medidas protectoras dependía de la calificación de la estatua como una parte de un bien inmueble, que era el fundo donde se había ubicado, o como un bien mueble independiente; y ello dado que las medidas protectoras enjuiciadas estaban previstas únicamente en la legislación de patrimonio histórico para los bienes calificados como inmuebles. Dados los hechos fácticos descritos en la Sentencia citada y la definición de bien inmueble del Código civil y sus modificaciones contenidas en la LPH de 1985, el Tribunal Supremo entendió que la estatua era parte de un bien inmueble y eran legales las limitaciones establecidas en los inmuebles colindantes ${ }^{10}$.

9 Así, en el f.j. 3 de la STC 6/2012 se afirma que la demanda tiene cuidado de especificar que en el conflicto se plantea únicamente que corresponde a la Generalitat la competencia para proteger los bienes controvertidos y que Aragón ha excedido los límites de sus competencias en materia de patrimonio histórico y cultural con invasión de sus propias competencias en esa materia, asumidas en el Estatuto de Autonomía. Y en el mismo f.j. 3 se afirma que en el escrito de demanda se puntualiza que la petición formulada al TC no es la determinación de la titularidad de dichos bienes sino la declaración que la potestad administrativa de tutela sobre el patrimonio histórico corresponde a la Generalitat. Ello se reitera también en el f.j.4.

10 En concreto, en la Sentencia del Tribunal Supremo de 22 de julio de 2009 se dice que a tenor de lo que dispone el Código Civil en el art. 334.4, son bienes inmuebles las estatuas, relieves, pinturas u otros objetos de uso u ornamentación, colocados en edificios o heredades por el dueño del inmueble en tal forma que revele el propósito de unirlos de un modo permanente al fundo. Sin duda este es el supuesto que contemplamos. Se trata de un conjunto escultórico monumental que posee un evidente interés artístico y que el Ayuntamiento de Madrid dispuso colocar en la Plaza de Salvador de Dalí que le da nombre, en tal forma que revela el propósito de unirlo de un modo permanente al fundo. Esa fue por otra parte la razón de decidir de la Sentencia de instancia cuando expuso que el conjunto escultórico en cuanto que construcción artística, debe ser considerado como inmueble. Pero donde tiene más fácil encaje es en el apartado $4^{\circ}$ del precepto cuando establece que tienen la misma consideración las estatuas, relieves, pinturas u otros objetos de uso u ornamentación, colocados en edificios o heredades por el dueño del inmueble en tal forma que revele el propósito de unirlos de un modo permanente al fundo. Pues bien, el peso del conjunto, la dificultad de su traslado el costo de su montaje y desmontaje, la preparación del terreno en que se ha de instalar, etc. no son circunstancias que califiquen el bien como de inmueble pero, en cambio, sí son reveladoras del propósito de la Administración de unirlos de modo permanente al fundo.

Por otra parte, en la citada Sentencia del Tribunal Supremo se afirma que la LPHE de 1985, en el artículo 15 , singulariza dentro de los bienes inmuebles y con la categoría de monumentos «las obras de escultura colosal» siempre que tengan interés artístico» y, desde luego el dolmen de Dalí cumple con creces, y esto no se pone en duda por nadie, esas dos condiciones; es una escultura colosal en tanto que estatua de tamaño mucho mayor que el natural, y su interés artístico es evidente dado el prestigio universal de su autor. Y encaja igualmente en la concepción que muestra la Ley madrileña de bien monumental y, por tanto inmueble, cuando en el art. 9.2.a) expresa que tiene esa condición la: «obra producto de la actividad humana de relevante interés cultural, histórico, arquitectónico, arqueológico, artístico, etnográfico, científico o técnico, con inclusión de los muebles, instalaciones y accesorios que expresamente se señalen como parte integrante del mismo y que por sí solos constituyan una unidad singular.» 
Desde la perspectiva indicada en la Sentencia del Tribunal Supremo citada y si las obras artísticas procedentes del Monasterio de Sigena formasen parte de este bien inmueble declarado de interés cultural, dicha declaración alcanzaría a las mismas. Postura que tendría su fundamento en los propios informes que justificaron su declaración como monumento y a los que se aludió en un apartado anterior y en la propia normativa aragonesa de patrimonio cultural ${ }^{11}$. Y obras que habrían sido depositadas transitoriamente por la destrucción de Monasterio o su posterior cierre temporal en una institución museística para su restauración y conservación con la correspondiente autorización administrativa; y que podrían ser objeto de reintegración al citado Monasterio, una vez que el mismo reuniera las condiciones necesarias para su conservación, como ya sucedió en otras ocasiones en el siglo $\mathrm{XX}^{12}$.

$\mathrm{E}$, incluso, aunque se calificaran como bienes muebles independientes y para determinar su régimen jurídico, sería necesario tener en cuenta el art. 27 de la LPH de 1985. En dicho precepto se dice que tendrán la consideración de bienes de interés cultural, en todo caso, los bienes muebles contenidos en un inmueble que haya sido objeto de dicha declaración y que ésta los reconozca como parte esencial de su historia. Vinculación que vendría fundamentada en los propios informes que motivaron la declaración del Monasterio como monumento nacional en el año 1923, según se expuso en un apar-

11 En este sentido, en el art. 15 de la Ley aragonesa 3/1999, de 10 de marzo, de patrimonio cultural, se dice que la declaración de un bien inmueble como de interés cultural comprenderá, sin necesidad de identificación específica, cuantos elementos puedan considerarse consustanciales con las construcciones y formen parte de las mismas o de su exorno, o lo hayan formado, aunque en el caso de poder ser separados constituyan un todo perfecto de fácil aplicación a otras construcciones o a usos distintos del suyo original, cualquiera que sea la materia de que estén formados y aunque su separación no perjudique visiblemente al mérito cultural del inmueble al que están adheridos. La declaración de bien de interés cultural de un bien inmueble incluirá los bienes muebles que se señalen como parte integrante del mismo.

En relación también con la consideración de las obras artísticas como parte del Monasterio, vid. el Dictamen 81/98, de 28 de julio, de la Comisión Jurídica Asesora del Gobierno de Aragón (num. 129, Memorias y Dictámenes 1998, Diputación General de Aragón, Zaragoza, 1999)

12 A estos efectos, en el artículo 18 de la LPHE de 1985 se dice que un bien inmueble declarado bien de interés cultural es inseparable de su entorno; y no se podrá proceder a su desplazamiento o remoción, salvo que resulte imprescindible por causa de fuerza mayor o de interés social y, en todo caso, conforme al procedimiento previsto en el art. 9.2 de la misma Ley. Y en el art. 19.1 de la LPHE se dice que en los monumentos declarados bienes de interés cultural no podrá realizarse obra interior o exterior que afecte directamente al inmueble o a cualquiera de sus partes integrantes o pertenencias sin autorización expresa de los organismos competentes para la ejecución de esta Ley. Por otra parte, en el art. 24.3 de la LPHE se establece que las obras que por razón de fuerza mayor hubieran de realizarse no darán lugar a actos de demolición que no sean estrictamente necesarios para la conservación del inmueble y requerirán en todo caso la autorización prevista en el art. 16.1 de la misma Ley, debiéndose prever además en su caso la reposición de los elementos retirados. En relación con los citados preceptos, vid. la bibliografía citada al inicio de este comentario. De forma similar se exige autorización para la salida temporal de los bienes muebles integrantes de un bien de interés cultural en el art. 35 de la Ley aragonesa 3/1999 antes citada.

Esta posibilidad de realizar depósitos en museos está prevista expresamente en relación con los museos de titularidad estatal en el art. 63 de la LPHE y de igual forma en la legislación sectorial. En cuanto al régimen de depósitos en el mismo art. 63 se establece que cuando se trate de objeto en depósito se respetará lo pactado al constituirse. Vid. los arts. 8 y ss. del Real Decreto 620/1987, de 10 de abril, por el que se aprobó el Reglamento de Museos de titularidad estatal y del sistema español de museos, en relación con los depósitos de bienes de interés cultural. 
tado anterior. Y, asimismo, habría que tener presente el art. 36.3 de la LPH de 1985. Artículo en el que se establece que excepcionalmente la Administración competente podrá ordenar el depósito de los bienes muebles en centros de carácter público en tanto no desaparezcan las causas que originaron dicha necesidad.

Partiendo de las limitaciones del pronunciamiento de la STC 6/2012 que se acaban de exponer, al haber excluido las cuestiones que afectan a la calificación y naturaleza de las obras artísticas depositadas y las relativas a la legalidad de la venta realizada y el ejercicio del derecho de retracto, en el apartado siguiente se examinará la resolución del conflicto de competencias por el TC.

\section{RESOLUCIÓN DEL CONFLICTO DE COMPETENCIAS A FAVOR DE LA COMUNIDAD AUTÓNOMA DE CATALUÑA Y CONSIDERACIÓN DE QUE ES LA COMPETENTE PARA CONSERVAR LAS OBRAS ARTÍSTICAS DEPOSITADAS EN LAS INSTITUCIONES MUSEÍSTICAS UBICADAS EN SU TERRITORIO. ALCANCE DEL FALLO}

Partiendo de la delimitación del objeto del conflicto de competencias descrito en el apartado anterior, la STC 6/2012 únicamente se pronuncia sobre quién es el titular de la competencia para continuar conservando las obras artísticas depositadas en instituciones museísticas catalanas, y no se alude ni directa ni indirectamente a la calificación de las obras artísticas y su vinculación al Monasterio de Sigena ni a la legalidad de la compra y del derecho de retracto ejercitado. En definitiva, únicamente se pronuncia sobre si debe continuar la Comunidad Autónoma de Cataluña ejercitando las competencias de conservación de las obras artísticas, sin plantearse ningún aspecto relativo a las condiciones a las que están sometidas. Teniendo presente esta limitación del alcance del objeto del conflicto, el TC va a declarar que la competencia de conservación corresponde a la Comunidad Autónoma de Cataluña por las razones que a continuación se indicarán.

En primer lugar, la STC 6/2012 parte de que la Comunidad Autónoma de Cataluña, tanto en su Estatuto de 1979 como en el de 2006, tiene competencia exclusiva en materia de patrimonio histórico, artístico y monumental y en materia de museos y otros centros de depósito cultural ${ }^{13}$; y que la Comunidad Autónoma de Aragón tiene también

13 En concreto, en el f.j 5 de la STC se dice que desde la aprobación del Estatuto de Autonomía de Cataluña de 1979 la Generalitat de Cataluña asumió la competencia exclusiva en materia de cultura (art. 9.4), patrimonio histórico, artístico, monumental, arquitectónico, arqueológico y científico (art. 9.5) y en materia de archivos, bibliotecas, museos y otros centros de depósito cultural que no sean de titularidad estatal (art. 9.6). Este marco normativo ha sido refrendado por el art. 127.1 del vigente Estatuto de 2006 (Ley Orgánica 6/2006, de 19 de julio, de reforma del Estatuto de Autonomía de Cataluña), el cual añade que, «en todo caso», esta competencia comprende «el patrimonio cultural», que, a su vez, incluye «en todo caso: Primero. La regulación y la ejecución de medidas destinadas a garantizar el enriquecimiento y la difusión del patrimonio cultural de Cataluña y a facilitar su acceso. Segundo. La inspección, inventario y restauración del patrimonio arquitectónico, arqueológico, científico, técnico, histórico, artístico, etnológico y cultural en general. Tercero. El establecimiento del régimen jurídico de las actuaciones sobre bienes muebles e inmuebles integrantes del patrimonio cultural de Cataluña y la determinación del régimen jurídico de los bienes inmuebles, así como la de- 
competencias exclusivas en materia de patrimonio cultural, histórico y artístico, de acuerdo con el Estatuto de 1982 y sus reformas de 1994 y 2007, y que en dicho Estatuto se atribuye, además, las políticas necesarias encaminadas a recuperar el patrimonio aragonés que se encuentre ubicado fuera del territorio de Aragón ${ }^{14}$.

En segundo lugar, y esto constituye uno de los elementos relevantes en la decisión, la STC 6/2012 considera que tanto la compra de las obras artísticas por la Comunidad Autónoma de Cataluña como el ejercicio del derecho de retracto por la Comunidad Autónoma de Aragón sobre las citadas obras son potestades administrativas ejercitadas para la conservación de las obras artísticas que se integran dentro de la competencia general en materia de patrimonio cultural, histórico y artístico ${ }^{15}$. Con ello se rechaza la alegación de

claración y la gestión de estos bienes con la excepción de aquéllos que sean de la titularidad del Estado. Cuarto. La protección del patrimonio cultural de Cataluña, que incluye la conservación, la reparación, el régimen de vigilancia y el control de los bienes, sin perjuicio de la competencia estatal para la defensa de los bienes integrantes de este patrimonio contra la exportación y la expoliación».

14 Así, en la STC, f.j.5, comentada se dice que, por lo que se refiere a la competencia en materia de cultura asumida por la Comunidad Autónoma de Aragón, en el artículo 36 de la redacción original de su Estatuto (Ley Orgánica 8/1982, de 10 de agosto) la Comunidad Autónoma de Aragón asume, en el marco de la legislación básica del Estado, la función de ejecución y desarrollo legislativo en materia de patrimonio cultural, histórico, artístico, monumental, arqueológico, arquitectónico de interés para la Comunidad Autónoma [art. 36.1 g)]. La reforma estatutaria efectuada por la Ley Orgánica 6/1994, de 24 de marzo, no alteró esta caracterización de la competencia estatutaria en la materia (art. 36.Uno.3). Sí lo hizo, en cambio, la reforma operada por la Ley Orgánica 5/1996, de 30 de diciembre, que incorporó el art. 35.1.33 que atribuye a la Comunidad Autónoma la competencia exclusiva sobre "patrimonio cultural, histórico, artístico, monumental, arqueológico, arquitectónico y científico de interés para la Comunidad Autónoma“.

Finalmente, la Ley Orgánica 5/2007, de 20 de abril, de reforma del Estatuto de Autonomía de Aragón, establece en su artículo 71.45 que corresponde a la Comunidad Autónoma la competencia exclusiva en la materia "patrimonio cultural, histórico, artístico, monumental, arqueológico, arquitectónico, científico y cualquier otro de interés para la Comunidad Autónoma, en especial las políticas necesarias encaminadas a recuperar el patrimonio aragonés que se encuentre ubicado fuera del territorio de Aragón”. Su art. 22, por otra parte, recoge entre los principios rectores de las políticas públicas, el principio de patrimonio cultural, según el cual "1. Los poderes públicos aragoneses promoverán la conservación, conocimiento y difusión del patrimonio cultural, histórico y artístico de Aragón, su recuperación y enriquecimiento. 2. En particular, los poderes públicos aragoneses desarrollarán las actuaciones necesarias para hacer realidad el regreso a Aragón de todos los bienes integrantes de su patrimonio cultural, histórico y artístico que se encuentran fuera de su territorio".

15 En concreto, en la STC, f.j.4, comentada se dice que debemos rechazar que la compraventa de los controvertidos bienes por parte de la Generalitat no supusiera actuación de potestad alguna, como sostiene la representación del Gobierno de Aragón. De la misma forma el ejercicio del derecho de retracto sobre aquellos bienes constituye un ejercicio de la competencia de ejecución en materia de patrimonio histórico por parte del Gobierno de Aragón, su previa adquisición por parte de la Generalitat se realizó, como sostiene su escrito de requerimiento de 16 de abril de 1998, en ejercicio de las competencias en materia de patrimonio cultural y de museos asumidas estatutariamente (arts. 9.5 y 9.6 del Estatuto de Autonomía de Cataluña), y en cumplimiento de lo dispuesto en la legislación sobre patrimonio histórico (arts. 6 y 8 de la LPHE y art. 40.3 del Real Decreto 111/1986).

Y, por lo que respecta al ejercicio del derecho de retracto por la Administración aragonesa, en la STC, f.j. 7, comentada se afirma que las Ordenes impugnadas por las que se acuerda ejercitar el derecho de retracto legal sobre los mencionados bienes constituyen efectivamente un ejercicio de la competencia de ejecución en materia de patrimonio histórico asumida por la Comunidad Autónoma de Aragón [art. $36.1 \mathrm{~g}$ ) del Estatuto de Autonomía de Aragón, posteriormente art. 35.1.33 del Estatuto de Autonomía], tal como admite el Letrado de dicha Comunidad en sus alegaciones. Ello es así porque la decisión de ejercitar tal derecho es un acto formal de la Comunidad Autónoma, que realiza como tal de conformidad con el art. 38 de la LPHE y los arts. 40, 41 y 42 del Real Decreto 111/1986, de 10 de enero, según reza el fundamento jurídico segundo de la Orden de 8 de 
la Comunidad aragonesa relativa a que una compra civil no es propiamente una potestad administrativa y confirma que las dos Comunidades Autónomas están ejercitando simultáneamente y de forma incompatible una misma competencia sobre unas mismas obras artísticas.

Y en tercer lugar, el criterio que se aplica en la STC 6/2012 para resolver el conflicto es el de territorialidad, es decir, el lugar donde se encuentran las obras. Aplicación que responde a las limitaciones del objeto del conflicto y la imposibilidad de pronunciarse y determinar la calificación de las obras artísticas y su vinculación al Monasterio y la legalidad de la venta y el ejercicio del derecho de retracto. Por ello, atribuye a la Comunidad Autónoma de Cataluña la competencia para continuar conservando los bienes en su territorio.

En concreto, en la STC 6/2012, f.j.6, comentada se afirma que en reiteradas ocasiones nos hemos referido al principio según el cual el territorio es elemento delimitador de los poderes públicos territoriales en el ejercicio de las competencias que les corresponden y, más en concreto, es elemento delimitador de las competencias de las Comunidades Autónomas en su relación con las demás Comunidades y con el Estado (con cita de las SSTC 44/1984, de 27 de marzo; 180/1992, de 16 de noviembre; 118/1996, de 27 de junio; y 132/1996, de 22 de julio), pues hemos indicado también que este principio no puede ser interpretado "en unos términos que impidan a las instancias autonómicas, en el ejercicio de sus propias competencias, adoptar decisiones cuyas consecuencias puedan proyectarse sobre otros lugares del territorio nacional" [SSTC 37/1981, de 16 de noviembre, f.j. 1; 150/1990, de 4 de octubre, f.j. 5; y 126/2002, de 23 de mayo, f.j. 9 a); y 168/2004, de 6 de octubre, f.j. 4].

Y sigue diciendo la STC 6/2012 comentada, f.j.8, que desde la consideración de que el objetivo de las competencias de las Comunidades Autónomas en materia de protección del patrimonio histórico es la preservación de los bienes de esta naturaleza y tomando en cuenta no sólo la señalada funcionalidad general del territorio en el entramado de distribución de competencias operado por la Constitución, los Estatutos de Autonomía y demás leyes integradas en el bloque de la constitucionalidad, sino también que nos encontramos ante la concurrencia de competencias en un mismo espacio físico y ante la falta de recurso a las técnicas de colaboración entre Comunidades Autónomas, debemos concluir que en el presente caso prevalece la competencia que corresponde a Cataluña, a cuyo

agosto de 1997. Los preceptos citados contemplan la posibilidad de retracto de determinados bienes culturales por parte de "los demás organismos competentes para la ejecución de esta Ley" (art. 38.4 de la LPHE), entre los que figuran aquellos que "en cada Comunidad Autónoma tengan a su cargo la protección del patrimonio histórico" [art. 6 a) de la misma ley], en este caso el Consejero de Educación y Cultura de la Diputación General de Aragón. La Generalitat de Cataluña también entiende que mediante las Órdenes impugnadas el Gobierno de Aragón habría ejercido las potestades inherentes a la tutela administrativa sobre el patrimonio artístico, si bien fuera de los límites competenciales y legales fijados en el bloque de la constitucionalidad.

Y ello es así para la STC 6/2012 dada la finalidad del derecho de retracto. En particular, en ella se afirma que la función que cumple el retracto en la legislación del patrimonio histórico es garantizar la protección de los bienes de esta naturaleza desde el entendimiento de que en determinadas ocasiones esta protección se va a realizar mejor en manos de la Administración. He aquí la finalidad de la atribución a las Comunidades Autónomas de la facultad de retracto; facultad que, de darse las circunstancias que precisaran de la actuación de preservación y protección del patrimonio, podrán, sin duda, ejercitarla frente a los particulares y frente a otras Administraciones públicas. 
cuidado - y como resultado de las más diversas circunstancias - se hallan los bienes relacionados en las órdenes dictadas por el Consejero de Educación y Cultura de la Diputación General de Aragón. Ciertamente, al ejercer su competencia sobre patrimonio histórico sobre los bienes que se hallan en su territorio — con independencia de cuál sea el origen de los mismos-, Cataluña viene cumpliendo la señalada función de preservación del patrimonio histórico y artístico de España, y resulta constitucionalmente congruente desde esta perspectiva, toda vez que los bienes sobre los que versa la controversia están en adecuadas condiciones de conservación en Cataluña, que los mismos permanezcan en la Comunidad Autónoma en la que se encuentran.

Por último, es preciso advertir que de los argumentos contenidos en la STC 6/2012 que se acaban de exponer, únicamente puede deducirse la conclusión de que la situación actual de conservación de las obras artísticas debe continuar en los términos en que se está realizando por la Administración catalana. Pero no es posible deducir ninguna otra consecuencia ni, en particular, que la Sentencia otorga un derecho de permanencia indefinida de las citadas obras artísticas en dichas instituciones museísticas catalanas ${ }^{16}$. Y ello por haber sido excluido del objeto del conflicto positivo de competencias la cuestión de fondo que subyace y que se centra en si dichas obras forman parte del Monasterio, que es un bien de interés cultural, y deben reintegrarse a él, cuando reúna las condiciones adecuadas; y que versa sobre la legalidad de la compra de las obras artísticas por la Generalitat y el ejercicio del derecho de retracto por la Administración aragonesa. Si los tribunales ordinarios optaran por la consideración de que son elementos del Monasterio, la cuestión que se plantearía a continuación es la reintegración al mismo de las obras artísticas, como ya ha sucedido en otras ocasiones en el siglo XX; punto sobre el que no se ha pronunciado la STC 6/2012.

\section{LA ATRIBUCIÓN DE LA COMPETENCIA PARA LA CONSERVACIÓN DE LAS OBRAS ARTÍSTICAS EN FONDOS MUSEÍSTICOS CATALANES A LA GENERALITAT DE CATALUNYA NO QUEDA AFECTADA POR LA POTESTAD PARA RECUPERAR EL PATRIMONIO CULTURAL ARAGONÉS FUERA DE SU TERRITORIO ATRIBUIDA A LA COMUNIDAD AUTÓNOMA DE ARAGÓN EN SU ESTATUTO DE AUTONOMÍA}

La atribución de la competencia a la Generalitat de Catalunya de conservación de las obras artísticas depositadas en sus instituciones museísticas, a la que se hizo referencia en el apartado anterior, no queda afectada por las previsiones específicas contenidas en el Estatuto de Autonomía de Aragón.

16 A estos efectos debe señalarse que tampoco la adquisición de la titularidad de las obras artísticas por la Generalitat de Catalunya conllevaría ese derecho de permanencia, al configurar la STC 6/2012 la compra como una potestad instrumental para hacer efectiva la conservación de las obras artísticas depositadas en sus instituciones. La continuidad de tales obras estaría en función de la resolución del fondo del asunto y, en particular, de la consideración de las mismas como partes del Monasterio, la reintegración de los elementos dispersos a este inmueble de interés cultural, etc. 
En concreto, en el art. 71.45 del Estatuto de Autonomía de Aragón, en su redacción dada por la Ley Orgánica 5/2007, de 20 de abril, de reforma del mismo, atribuye a la Comunidad Autónoma de Aragón la competencia exclusiva en la materia de patrimonio cultural, histórico, artístico y monumental y cualquier otro de interés para la Comunidad Autónoma, y en especial las políticas necesarias encaminadas a recuperar el patrimonio aragonés que se encuentre ubicado fuera del territorio de Aragón. Y en el art. 22.2 del mismo Estatuto se establece que los poderes públicos aragoneses desarrollarán las actuaciones necesarias para hacer realidad el regreso a Aragón de todos los bienes integrantes de su patrimonio cultural, histórico y artístico que se encuentran fuera de su territorio ${ }^{17}$.

Esa falta de afección es justificada por la STC 6/2012 comentada. En particular, en ella se afirma que el ejercicio de las potestades públicas por la Comunidad Autónoma de Aragón ha de hacerse, en todo caso, en términos conformes con el orden competencial y atendiendo los contornos posibles de las mismas. En relación al primero de estos aspectos se debe recordar que en el presente caso el recurso al derecho de retracto como instrumento de la política de recuperación del patrimonio cultural ubicado fuera del territorio de Aragón — que se realiza en ejercicio de la competencia exclusiva sobre patrimonio histórico y cultural - choca con la competencia autonómica catalana en materia de preservación del patrimonio que ha de entenderse que se extiende a aquel que está en su territorio, independientemente de su origen (art. 127 del Estatuto de Autonomía de Cataluña).

Desde la consideración — sigue diciendo la STC 6/2012 comentada— de que el objetivo de las competencias de las Comunidades Autónomas en materia de protección del patrimonio histórico es la preservación de los bienes de esta naturaleza y tomando en cuenta la territorialidad del ejercicio de la competencia, en el presente caso prevalece la competencia que corresponde a Cataluña.

La decisión contenida en la STC 6/2012 que se acaba de exponer parte de que la previsión del Estatuto aragonés no constituye propiamente una competencia oponible a las competencias en materia de patrimonio cultural de otras Comunidades Autónomas, sino una habilitación a la Comunidad Autónoma de Aragón para que actúe de una forma concreta dentro de un marco competencial ${ }^{18}$. De ahí la referencia a las técnicas de colaboración para hacer efectiva dicha previsión estatutaria y la primacía de las competencias de la Generalitat, en caso contrario. Estas afirmaciones contenidas en la STC de la pre-

17 En relación con la regulación del patrimonio cultural aragonés, vid. L.POMED SANCHEZ «Patrimonio cultural», en A.EMBID, Derecho público aragonés, 4ª ed., El Justicia, Zaragoza, 2008, págs. 626 y ss.; y L.POMED SANCHEZ (Dir.), Estudio sistemático de la Ley del Patrimonio Cultural Aragonés, Cortes de Aragón, Zaragoza.

18 En este sentido, por ejemplo, en el f.j.8 de la STC 6/2012 se afirma que una de las políticas a emprender por los poderes públicos aragoneses es el procurar el regreso a Aragón de todos lo bienes integrantes de su patrimonio cultural, histórico y artístico que se encuentran fuera de su territorio; y es claro igualmente que, en el desempeño de tales políticas de recuperación de bienes, el Gobierno autonómico podría recurrir al ejercicio de potestades públicas como el retracto y otras que pudieran servir al fin de recuperación del patrimonio. Pero el ejercicio de tales potestades ha de hacerse en términos conformes con el orden competencial. 
visión estatutaria no son aceptadas por los dos votos particulares formulados a la STC $6 / 2012^{19}$.

La decisión del TC expuesta resulta de relevancia para la interpretación de previsiones similares contenidas en otros Estatutos y, en particular, para determinar el alcance de la regulación incluida en el Estatuto de Cataluña relativa a la recuperación de bienes culturales situados fuera de su territorio. Tales menciones no podrían oponerse a otras Comunidades Autónomas o el Estado para recuperar bienes culturales, sin perjuicio de la utilización de las técnicas de colaboración ${ }^{20}$.

De lo expuesto en los diversos apartados anteriores de este comentario de la STC 6/2012, y a modo de resumen, se deduce que el alcance de dicha Sentencia es limitado y vinculado a las características especiales del supuesto de hecho y delimitación del objeto del proceso realizado por el propio Tribunal. Partiendo de estas premisas, el TC ha declarado que la Comunidad Autónoma de Cataluña es competente para la conservación de las obras artísticas depositadas en sus instituciones museísticas, como venía haciendo hasta estos momentos. Declaración a la que no puede oponerse la actuación de una Comunidad Autónoma pretendiendo recuperar su patrimonio cultural, mediante el ejercicio del derecho de retracto. Dicho fallo del TC, no obstante, no conlleva pronunciamiento alguno sobre la naturaleza de las obras artísticas, ni su titularidad, ni el ejercicio del derecho de retracto, ni la permanencia indefinida de dichas obras en las instituciones museísticas catalanas. En definitiva, el alcance de la STC es limitado y no decide sobre la cuestión de fondo que subyace y que consiste en dónde deben ubicarse de forma definitiva las obras artísticas procedentes del Monasterio de Sigena, una vez que finalice la situación temporal derivada de los depósitos en instituciones museísticas catalanas originados por la destrucción y cierre del citado Monasterio.

19 Así, en el voto particular formulado por la magistrada Elisa Pérez Vera y al que se adhiere el magistrado Ramón Rodríguez Arribas, se considera que las resoluciones aragonesas por las que se ejercita el derecho de retracto han sido dictadas en ejecución de las previsiones del Estatuto de Autonomía de Aragón y que el cuestionamiento de las mismas supone también el del precepto estatutario; y para llegar a esto último el procedimiento debería haberse tramitado de acuerdo con lo dispuesto en el art. 67 de la Ley Orgánica del Tribunal Constitucional en la forma prevista para el recurso de inconstitucionalidad. Ello hubiera permitido al Tribunal conocer la posición del abogado del Estado al respecto, así como la de las instancias autonómicas no sólo sobre el ejercicio del derecho de retracto sino también sobre el alcance de las competencias asumidas en el Estatuto. También es contraria a esta configuración el voto particular formulado por el magistrado Francisco José Hernando Santiago y al que se adhiere el magistrado Francisco Pérez de los Cobos Orihuel, en el que se disiente de la argumentación contenida en la Sentencia y, en particular, de la aplicación del criterio de territorialidad, dado que en tal caso la previsión del Estatuto aragonés deviene en vacía y no tiene alcance, al menos respecto de bienes que se encuentren en posesión de instituciones públicas de Cataluña.

20 Por ejemplo, en el art. 127 c) tercero del Estatuto de Autonomía de Cataluña de 2006 se dice que corresponde a la Generalitat la competencia en materia de cultura que comprende en todo caso los archivos, las bibliotecas, los museos y los otros centros de depósito cultural que no son de titularidad estatal, y que a su vez esta última, incluye la conservación y la recuperación de los bienes que integran el patrimonio documental y bibliográfico catalán. Esta última referencia a la recuperación del patrimonio documental debe interpretarse en el sentido indicado en la STC 6/2012 comentada, por lo que únicamente puede hacerse efectiva utilizando técnicas de colaboración y respetando el orden competencial. En este marco de colaboración debe entenderse también las referencias a traslados de documentos de instituciones públicas catalanas a Cataluña contenidas en la Ley 21/2005, de 17 de noviembre, por la que se restituyen a la Generalidad de Cataluña de los documentos incautados con motivo de la guerra civil y que se encontraban custodiados en el Archivo general de la guerra civil española de Salamanca. 
TITLE: Comment on STC 6/2012. The competence of Autonomus Communities on conservation of works of art and cultural heritage placed in museums

ABSTRACT: The recent sentence of the Constitutional Court 6/2002, of 18 January 2012, which has solved to positive conflict of jurisdiction raised between the Autonomous Communities of Catalonia and Aragon, there is been pronounced on the conservation of artworks temporarily deposited in institutions museum. Specifically, it has been argued that the regional administration competent for conservation is the one in whose territory they it plows located such work. However, the scope of such to statement cannot be separated from the unique characteristics of the factual marries on which is pronounced the TC and the object of the constitutional process itself delimited in the STC 6/2012. Scope that is discussed in this commentary jurisprudential and from which it is clear that the statements contained in the STC 6/2002 may only be applied to the assumptions

RESUMEN: La reciente Sentencia del Tribunal Constitucional 6/2002, de 18 de enero de 2012 (en adelante, STC 6/2002), que ba resuelto un conflicto positivo de competencias planteado entre las Comunidades Autónomas de Cataluña y A ragón, se ha pronunciado sobre una cuestión de gran relevancia en el ámbito de la conservación de las obras artísticas depositadas temporalmente en instituciones museísticas. En concreto, en ella se ha afirmado que la Administración autonómica competente para su conservación es aquélla en cuyo territorio se encuentren ubicadas dichas obras. No obstante, el alcance de tal declaración no puede separarse de las características singulares del supuesto de becho sobre el que se pronuncia el TC y del objeto del propio proceso constitucional delimitado en la STC 6/2012. Alcance que se examina en este comentario jurisprudencial y del que se deduce que las declaraciones contenidas en la STC 6/2002 únicamente pueden aplicarse a los supuestos con las características expuestas en la STC 6/2012.

Key Words: Positive conflict of jurisdiction. Autonomous Communities. Conservation

Palabras Clave: Patrimonio histórico. Competencias de las Comunidades Autónomas. Conflictos de competencias.

FECHA DE RECEPCIÓN: 2.06.2012 FeCHA DE ACEPTACIÓN: 19.07.2012

UNED. Teoría y Realidad Constitucional, núm. 30, 2012, pp. 499-514. 